\title{
Serum Levels of Matrix Metalloproteinase (MMP) 9, a Risk Factor for Acute Coronary Syndrome, Are Reduced Independently of Serum MMP-3 by Anti-TNF- $\alpha$ Antibody (Infliximab) Therapy in Patients With Rheumatoid Arthritis
}

\author{
Takuya Kotani ${ }^{1}$, Tohru Takeuchi ${ }^{1, *}$, Shinji Takai ${ }^{2}$, Shuzo Yoshida ${ }^{1}$, Kenichiro Hata $^{1}$, Koji Nagai $^{1}$, \\ Daisuke Wakura $^{1}$, Kentaro Isoda ${ }^{1}$, Shigeki Makino ${ }^{1}$, and Toshiaki Hanafusa ${ }^{1}$ \\ ${ }^{1}$ Department of Internal Medicine (I), ${ }^{2}$ Department of Pharmacology, Osaka Medical College, \\ Takatsuki, Osaka 569-8686, Japan
}

Received May 28, 2012; Accepted June 14, 2012

\begin{abstract}
Matrix metalloproteinase 9 (MMP-9) is a risk factor for cardiovascular events. The serum MMP-9 levels were measured before and 2 weeks after treatment with infliximab $(3 \mathrm{mg} / \mathrm{kg})$ in 12 rheumatoid arthritis (RA) patients. The serum average MMP-9 level was $238.5 \mathrm{ng} / \mathrm{ml}$ before treatment with infliximab in RA patients (normal range: less than $43.8 \mathrm{ng} / \mathrm{ml}$ ). Infliximab reduced the serum average MMP-9 level significantly $(161.66 \mathrm{ng} / \mathrm{ml}, P=0.0425)$. The serum MMP-9 level was high in the RA patients with active disease, and it was reduced by infliximab independently of the reduction in disease activity. Thus, infliximab may reduce the risk of cardiovascular events directly.
\end{abstract}

Keywords: rheumatoid arthritis, matrix metalloproteinase 9, acute coronary syndrome

Rheumatoid arthritis (RA) is a systemic autoimmune disease mainly presenting as joint destruction. RA patients have a higher risk of developing atherosclerosis and show higher rates of cerebral infarction and cardiovascular events, in comparison to healthy individuals. The incidence of coronary artery disease in RA patients has been reported to be four times higher than in the general population. Therefore, it is important to examine risk factors associated with the development of cardiovascular events.

Matrix metalloproteinase 9 (MMP-9) is an enzyme that degrades components of the extracellular matrix, such as type IV collagen, fibronectin, and vitronectin, and is an inflammatory mediator involved in the development of cardiovascular events (1). Macrophages infiltrate into the coronary artery plaques and strongly express MMP-9. MMP-9 acts on the fibrous membrane of coronary artery plaques to induce plaque disruption, thereby being directly involved in the development of cardiovascular events (1). The serum MMP-9 level is higher in

*Corresponding author. t-takeuchi@poh.osaka-med.ac.jp Published online in J-STAGE on August 8, 2012 (in advance) doi: 10.1254/jphs.12129SC patients with coronary artery disease and is a risk factor of cardiovascular events (2).

The expression of MMPs, such as MMP-3 and MMP9 , is increased in the synovium of RA patients, and the levels of MMPs in their serum and synovial fluid are higher than in normal subjects (3). MMPs are involved in bone and cartilage destruction in RA. In particular, the serum MMP-3 levels have been shown to correlate with the degree of synovitis, and the serum MMP-3 level is also used as a marker of synovitis. On the other hand, the role of MMP-9 in RA remains unclear.

In this study, we measured the serum MMP-9 level in RA patients and analyzed the effects of an anti-TNF- $\alpha$ antibody, infliximab, on the serum MMP-9 level.

The subjects included 12 RA patients who had received infliximab therapy in the Department of Internal Medicine (I), Osaka Medical College, between September 2006 and September 2009. Written informed consent was obtained from all subjects. The study conformed to the Declaration of Helsinki. Patient anonymity was maintained during data collection, and the security of personal information was strictly controlled. Infliximab was administered at a dose of $3 \mathrm{mg} / \mathrm{kg}$ on weeks 0,2 , and 6 and then at 8 -week intervals thereafter. Blood samples 
were collected from all 12 patients before and 2 weeks after infliximab administration (the day after the second administration of infliximab), and the serum was stored at $-20^{\circ} \mathrm{C}$ before the measurement of MMP-9. The clinical data, including gender, age, stage and class according to the Steinbrocker system, disease duration, other treatment [methotrexate (MTX) and prednisolone (PSL) doses], and disease activity score 28 - C-reactive protein (CRP) (DAS28-CRP), were obtained from the patient's clinical charts. The serum CRP, rheumatoid factor (RF), and MMP-3 levels as well as the erythrocyte sedimentation rate (ESR) were measured before and 2 weeks after infliximab therapy. As atherosclerotic status, cardiovascular risks were evaluated according to the Japanese Society of Hypertension Guidelines for the Management of Hypertension (JSH 2009) (4).

MMP-3 was measured by latex turbiimetric immunoassay (Daiichi Fine Chemical, Toyama). The cut-off values for MMP-3 were $121.0 \mathrm{ng} / \mathrm{ml}$ for males and 59.7 $\mathrm{ng} / \mathrm{ml}$ for females.

The serum MMP-9 levels were measured before and 2 weeks after infliximab therapy. The MMP-9 levels were measured using an MMP-9 activity assay kit (Amersham Bioscience, Piscataway, NJ, USA), as described previously (5). Briefly, 32-fold dilutions of sera were added to the wells of a 96-well plate coated with an anti-MMP-9 antibody. After washing, $p$-aminophenylmercuric acetate was added to the wells, as the substrate for MMP-9 and its metabolite was detected at $405 \mathrm{~nm}$.
Wilcoxon's rank sum test was used to assess the serum MMP-9 levels before and 2 weeks after infliximab treatment. Spearman's rank correlation was used to assess the association between markers of RA disease activity (DAS28-CRP, CRP, ESR, MMP-3, and RF) vs. serum MMP-9 levels. Statistical calculations were performed with the JMP, version 8.0 software package (SAS Institute, Cary, NC, USA).

The patient profiles are shown in Table 1 . Of the 12 patients, 8 were female and 4 were male with a mean age of 58.0 years (range, 37 - 77 years). The RA stage classification revealed 2 patients with stage I of the disease, 4 with stage II, 4 with stage III, and 2 with stage IV. For the RA classes, 3 patients were in class 1,7 in class 2 , and 2 in class 3 . The mean disease duration was 42.6 months (range, 9-120 months). The mean doses of MTX and PSL were $7.5 \mathrm{mg} /$ week and $4.2 \mathrm{mg} /$ day, respectively. The doses of MTX and PSL were not changed during the first two weeks of infliximab administration. Smoking history, body mass index (BMI) greater than 25 $\left(\mathrm{kg} / \mathrm{m}^{2}\right)$, high-normal blood pressure, and grade I hypertension were observed in one, two, one, and three patients, respectively. Hyperlipidemia was observed in two patients. Diabetes mellitus was not detected in any patients. In cardiovascular risk stratification, nine patients were classified as no additive risk, two patients as low risk, and one patient as moderate risk.

The mean DAS28-CRP, RF, CRP, ESR, and serum MMP-3 levels before infliximab therapy were $4.63 \pm 0.18$,

Table 1. Patient profiles

\begin{tabular}{|c|c|c|c|c|c|c|c|c|c|c|c|c|}
\hline Case & Sex & $\begin{array}{l}\text { Age } \\
\text { (year) }\end{array}$ & Stage/Class & $\begin{array}{l}\text { Disease duration } \\
\quad \text { (month) }\end{array}$ & $\begin{array}{c}\text { MTX } \\
\text { (mg/week) }\end{array}$ & $\begin{array}{c}\text { PSL } \\
\text { (mg/day) }\end{array}$ & Smoking & BMI & $\begin{array}{c}\mathrm{BP} \\
(\mathrm{mmHg})\end{array}$ & HL & $\mathrm{DM}$ & $\begin{array}{l}\text { Cardiovascular } \\
\text { risk strata }\end{array}$ \\
\hline 1 & $\mathrm{~F}$ & 70 & III/1 & 120 & 8 & 7.5 & - & 19.3 & $128 / 78$ & - & - & NAR \\
\hline 2 & $\mathrm{~F}$ & 37 & $\mathrm{I} / 2$ & 36 & 4 & 5 & - & 19.4 & $98 / 56$ & - & - & NAR \\
\hline 3 & F & 50 & $\mathrm{I} / 2$ & 16 & 8 & 0 & - & 20.1 & $96 / 60$ & - & - & NAR \\
\hline 4 & F & 55 & III/1 & 15 & 4 & 0 & - & 23.2 & $159 / 96$ & - & - & LR \\
\hline 5 & M & 60 & $\mathrm{II} / 2$ & 9 & 8 & 0 & - & 17.3 & $135 / 77$ & - & - & NAR \\
\hline 6 & $\mathrm{M}$ & 60 & $\mathrm{IV} / 3$ & 13 & 14 & 0 & - & 19.1 & $123 / 68$ & - & - & NAR \\
\hline 7 & F & 60 & $\mathrm{III} / 2$ & 60 & 8 & 0 & - & 24.6 & $148 / 96$ & - & - & LR \\
\hline 8 & M & 48 & $\mathrm{III} / 2$ & 18 & 8 & 12 & - & 23.3 & $120 / 88$ & - & - & NAR \\
\hline 9 & $\mathrm{M}$ & 68 & $\mathrm{II} / 2$ & 20 & 6 & 5 & + & 21.3 & $108 / 66$ & - & - & NAR \\
\hline 10 & $\mathrm{~F}$ & 51 & II/1 & 48 & 8 & 10 & - & 27.6 & $140 / 90$ & + & - & MR \\
\hline 11 & $\mathrm{~F}$ & 77 & $\mathrm{IV} / 3$ & 36 & 4 & 2 & - & 21.4 & $122 / 70$ & - & - & NAR \\
\hline 12 & $\mathrm{~F}$ & 60 & $\mathrm{II} / 2$ & 120 & 10 & 9 & - & 27 & $112 / 62$ & + & - & NAR \\
\hline Average & & 58 & & 42.6 & 7.5 & 4.2 & & & & & & \\
\hline
\end{tabular}

Stage/Class, stage and class according to the Steinbrocker system; MTX, methotrexate; PSL, prednisolone; BMI, body mass index; BP, blood pressure; HL, hyperlipidemia; DM, diabetes mellitus; Cardiovascular risk strata according to the Japanese Society of Hypertension Guidelines for the Management of Hypertension (JSH 2009) (4); NAR, no additive risk; LR, low risk; MR, moderate risk. 
$181.4 \pm 76.0 \quad \mathrm{IU} / \mathrm{ml}, \quad 2.34 \pm 0.52 \mathrm{mg} / \mathrm{dl}, \quad 39.9 \pm 7.50$ $\mathrm{mm} / \mathrm{h}$, and $199.4 \pm 39.8 \mathrm{ng} / \mathrm{ml}$, respectively. DAS28CRP, RF, CRP, ESR, and serum MMP-3 levels were significantly reduced after infliximab therapy $(P=0.0005$, $0.002,0.0005,0.0112$, and 0.0005 , respectively). The mean serum MMP-9 levels before infliximab therapy were high, at $238.5 \pm 25.7 \mathrm{ng} / \mathrm{ml}$ (range, $96.51-390.34$ $\mathrm{ng} / \mathrm{ml}$; normal level, less than $43.8 \mathrm{ng} / \mathrm{ml}$ ). The serum MMP-9 levels after treatment were significantly $(P=0.0425)$ lower than before treatment, at $161.7 \pm 25.2$ $\mathrm{ng} / \mathrm{ml}$ as shown in Fig. 1.

The correlations between the changes in the serum MMP-3/MMP-9 levels ( $\Delta$ sMMP-3/ $\Delta$ sMMP-9) and in the disease activity indicators of RA ( $\triangle \mathrm{DAS} 28-\mathrm{CRP}, \triangle \mathrm{RF}$, $\triangle \mathrm{CRP}, \triangle \mathrm{ESR}$, and $\triangle \mathrm{sMMP}-3$ ) and $\triangle \mathrm{sMMP}-9$ after infliximab therapy are shown in Table 2 . There was no signifi-

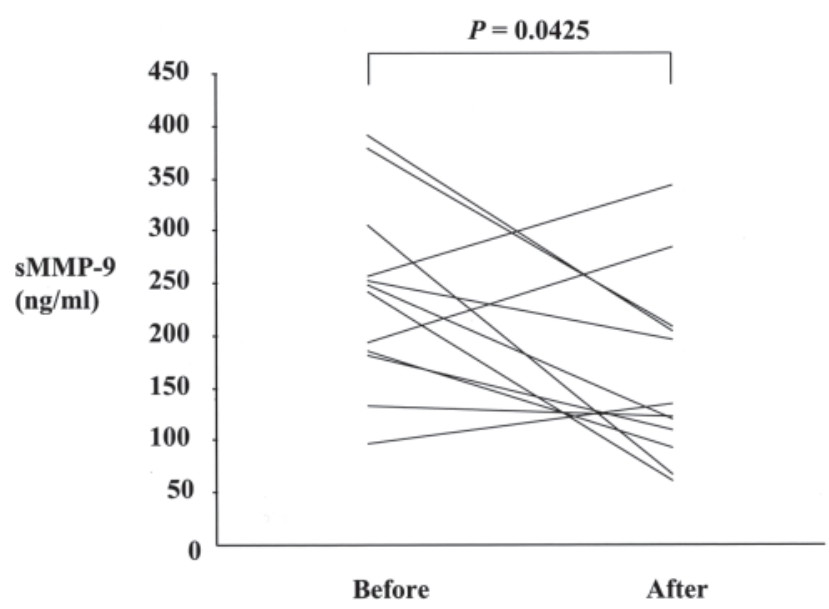

Fig. 1. The sMMP-9 levels before and after infliximab therapy. The sMMP-9 levels after treatment were significantly $(P=0.0425)$ lower than those before treatment. sMMP-9, serum matrix metalloproteinase 9; Before, before infliximab therapy; After, after infliximab therapy.

Table 2. Correlation between changes in serum MMP-3/MMP-9 activity and disease activity indicators of RA after infliximab therapy $\triangle$ SMMP-3 $\triangle$ sMMP-9

\begin{tabular}{lccc} 
& Median value & $P$ & $P$ \\
\hline$\triangle \mathrm{DAS} 28-\mathrm{CRP}$ & $1.97 \pm 0.20$ & 0.875 & 0.505 \\
$\Delta \mathrm{RF}(\mathrm{IU} / \mathrm{ml})$ & $45.97 \pm 24.64$ & 0.972 & 0.423 \\
$\Delta \mathrm{CRP}(\mathrm{mg} / \mathrm{dl})$ & $2.00 \pm 0.46$ & $0.048^{*}$ & 0.503 \\
$\Delta \mathrm{ESR}(\mathrm{mm} / \mathrm{h})$ & $16.75 \pm 5.88$ & 0.148 & 0.077 \\
$\Delta \mathrm{sMMP}-3(\mathrm{ng} / \mathrm{ml})$ & $114.27 \pm 39.30$ & - & 0.979 \\
$\Delta \mathrm{sMMP}-9(\mathrm{ng} / \mathrm{ml})$ & $76.88 \pm 31.80$ & 0.979 & - \\
\hline
\end{tabular}

$\Delta$, change between before and after infliximab therapy; DAS28-CRP, disease activity score 28 - C-reactive protein (11); RF, rheumatoid factor; CRP, C-reactive protein; ESR, erythrocyte sedimentation rate; MMP, matrix metalloproteinase; $* P<0.05$. cant correlation between $\triangle \mathrm{sMMP}-9$ and the changes in the RA disease activity indicators. In particular, no significant correlation was observed between 4 sMMP-9 and $\triangle$ sMMP-3.

Activated macrophages infiltrate the synovial tissue of RA patients and produce inflammatory cytokines such as TNF- $\alpha$. These inflammatory cytokines act on synovial cells, chondrocytes, and fibroblasts to induce MMP-3 expression (6). In addition, TNF- $\alpha$ acts on macrophages and neutrophils to induce MMP-9 expression (7). If the main site of MMP-3 and -9 production is the inflamed synovial tissue in RA patients, these MMPs should change in parallel with the disease activity. The present results showed that the change in the serum MMP-3 levels correlated with changes in CRP, but not with the change in the serum MMP-9 levels. This may be due to the fact that these MMPs in RA patients are also produced at sites other than the synovial membrane, or that inflammatory factors other than TNF- $\alpha$ may also regulate the production of these MMPs.

In recent years, atherosclerotic lesions have been described as the inflammation of blood vessels and resemble synovial lesions in RA (8). In atherosclerotic lesions, inflammatory cells such as macrophages infiltrate the arterial wall and produce large amounts of inflammatory cytokines such as TNF- $\alpha(8,9)$. Activated macrophages produce MMP-9 (1). Serum MMP-9 levels in patients with coronary artery disease are high and are correlated with the incidence of cardiovascular events (2). Atherosclerosis is accelerated in RA patients in comparison to healthy subjects due to the effect of underlying diseases and medication. MMP-9 production might also increase in the atherosclerotic lesions in RA patients.

Previous studies have reported that anti-TNF- $\alpha$ therapy inhibits the development of cardiovascular events in RA patients (10). This inhibition has been ascribed to the improvement of insulin resistance (11), endothelial function (12), and arterial wall stiffness (13). Anti-TNF- $\alpha$ blockades are associated with the reduction of carotid intima-media thickness (14), and the induction of hyperadiponectinemia (15). The present data suggest that the reduction of serum MMP-9 levels by anti-TNF- $\alpha$ therapy may also help to inhibit the progression of cardiovascular events.

Kulimiuk et al. measured the serum MMP-3 and -9 levels before and after infliximab administration during long-term (64 weeks) follow-up in 9 patients with RA as markers of arthritis, but not as risk factors for cardiovascular events (16). They reported that both the serum MMP-3 and -9 levels reached a minimum 6 weeks after the start of infliximab administration, but gradually increased thereafter. Concerning the reasons for the increases in these levels that transiently decreased during 
long-term follow-up, the results suggest that anti-infliximab antibody production reduced the effects of infliximab. To maintain the effects of infliximab for a long period and reduce the risk of cardiovascular events, infliximab should be combined with a sufficient volume of immunosuppressive drugs, such as MTX, so that antiinfliximab antibody production may be inhibited. In addition, when the effects of infliximab become impaired, this drug must be switched to other biological preparations to inhibit inflammation in RA patients.

In conclusion, the serum MMP-9 level was high in the RA patients with active disease, and infliximab reduces the serum MMP-9 levels, independently of the reduction of disease activity markers including MMP-3. This may result in preventing the development of cardiovascular events. However, in this work the number of patients studied and the observation period were limited. It will be necessary to accumulate a larger number of patients and to perform long-term observations to confirm this possibility.

\section{References}

1 Galis ZS, Sukhova GK, Lark MW, Libby P. Increased expression of matrix metalloproteinases and matrix degrading activity in vulnerable regions of human atherosclerotic plaques. J Clin Invest. 1994;94:2493-2503.

2 Blankenberg S, Rupprecht HJ, Poirier O, Bickel C, Smieja M, Hatner G, et al; AtheroGene Investigators. Plasma concentrations and genetic variation of matrix metalloproteinase 9 and prognosis of patients with cardiovascular disease. Circulation. 2003;107: $1579-1585$.

3 Yoshihara Y, Nakamura H, Obata K, Yamada H, Hayakawa T, Fujikawa K, et al. Matrix metalloproteinases and tissue inhibitors of metalloproteinases in synovial fluids from patients with rheumatoid arthritis or osteoarthritis. Ann Rheum Dis. 2000;59: 455-461.

4 Ogihara T, Kikuchi K, Matsuoka H, Fujita T, Higaki J, Horiuchi M, et al. The Japanese Society of Hypertension Guidelines for the Management of Hypertension (JSH 2009). Hypertens Res. 2009;32:3-107.

5 Fujimoto N, Hosokawa N, Iwata K, Shinya T, Okada Y, Hayakawa $\mathrm{T}$. A one-step sandwich enzyme immunoassay for inactive precursor and complexed forms of human matrix metalloproteinase 9 (92 kDa gelatinase/type IV collagenase, gelatinase B) using monoclonal antibodies. Clin Chim Acta. 1994;231:79-88.

6 MacNaul KL, Chartrain N, Lark M, Tocci MJ, Hutchinson NI. Discoordinate expression of stromelysin, collagenase, and tissue inhibitor of metalloproteinases-1 in rheumatoid human synovial fibroblasts. Synergistic effects of interleukin-1 and tumor necrosis factor-alpha on stromelysin expression. J Biol Chem. 1990; 265:17238-17245.

7 Kaneko M, Tomita T, Nakase T, Ohsawa Y, Seki H, Takeuchi E, et al. Expression of proteinases and inflammatory cytokines in subchondral bone regions in the destructive joint of rheumatoid arthritis. Rheumatology (Oxford). 2001;40:247-255.

8 Montecucco F, Mach F. Common inflammatory mediators orchestrate pathophysiological processes in rheumatoid arthritis and atherosclerosis. Rheumatology (Oxford). 2009;48:11-22.

9 McKellar GE, McCarey DW, Sattar N, McInnes IB. Role for TNF in atherosclerosis? Lessons from autoimmune disease. Nat Rev Cardiol. 2009;6:410-417.

10 Dixon WG, Watson KD, Lunt M, Hyrich KL, Silman AJ, Symmons DP; British Society for Rheumatology Biologics Register. Reduction in the incidence of myocardial infarction in patients with rheumatoid arthritis who respond to anti-tumor necrosis factor alpha therapy: results from the British Society for Rheumatology Biologics Register. Arthritis Rheum. 2007;56: 2905-2912.

11 Gonzalez-Gay MA, Gonzalez-Juanatey C, Vazquez-Rodriguez TR, Miranda-Filloy JA, Llorca J. Insulin resistance in rheumatoid arthritis: the impact of the anti-TNF-alpha therapy. Ann N Y Acad Sci. 2010;1193:153-159.

12 Sidiropoulos PI, Siakka P, Pagonidis K, Raptopoulou A, Kritikos $\mathrm{H}$, Tsetis D, et al. Sustained improvement of vascular endothelial function during anti-TNF alpha treatment in rheumatoid arthritis patients. Scand J Rheumatol. 2009;38:6-10.

13 Wong M, Oakley SP, Young L, Jiang BY, Wierzbicki A, Panayi $\mathrm{G}$, et al. Infliximab improves vascular stiffness in patients with rheumatoid arthritis. Ann Rheum Dis. 2009;68:1277-1284.

14 Del Porto F, Laganà $\mathrm{B}$, Lai $\mathrm{S}$, Nofroni I, Tinti F, Vitale M, et al. Response to anti-tumour necrosis factor alpha blockade is associated with reduction of carotid intima-media thickness in patients with active rheumatoid arthritis. Rheumatology (Oxford). 2007; 46:1111-1115.

15 Nishida K, Okada Y, Nawata M, Saito K, Tanaka Y. Induction of hyperadiponectinemia following long-term treatment of patients with rheumatoid arthritis with infliximab (IFX), an anti-TNFalpha antibody. Endocr J. 2008;55:213-216.

16 Klimiuk PA, Sierakowski S, Domyslawska I, Chwiecko J. Effect of repeated infliximab therapy on serum matrix metalloproteinases and tissue inhibitors of metalloproteinases in patients with rheumatoid arthritis. J Rheumatol. 2004;31:238-242. 